\title{
Kapitel 8. \\ Nonnos und seine Zeit - die Dionysiaka im Kontext
}

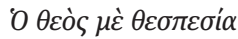

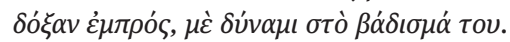

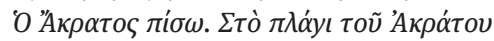

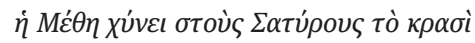

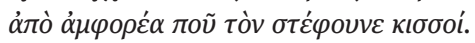

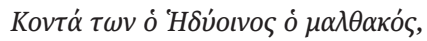

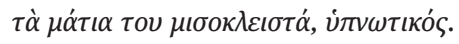

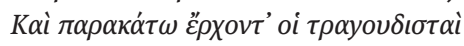

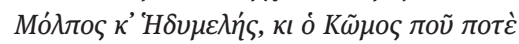

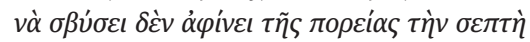

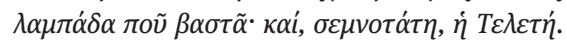

Konstantinos Kavafis ${ }^{1}$

\subsection{Ampelos und die Ästhetik der Spätantike}

Extreme Urteile über Sprache und Stil des Nonnos sind charakteristisch für die tendenzielle Abwertung und Ablehnung der Poetik der Dionysiaka, die noch zu Beginn des 20. Jhs. in der Klassischen Philologie und darüber hinaus vorherrschte. ${ }^{2}$ Da Ordnung im Sinne eines Ursache-Wirkung-Prinzips und einer Kausalität der Erzählung dieser Poetik ebenso fremd ist wie eine systematisch ausgestaltete Chronologie und konzinne Zeit- und Raumverhältnisse, wurde der Autor als unfähig angesehen, ein Epos nach traditionellem homerischen Muster zu komponieren. Die zahlreichen Einzelepisoden in der Erzählung wurden als bloße Nebenschauplätze und überflüssige Zutaten abgetan, die, wenn überhaupt, nur äußerst dürftig mit der sog. Haupthandlung um Dionysos' Kindheit, Jugend und Mannestaten in Verbindung zu bringen seien. Die Dionysiaka wurden als Kumulation sämtlicher Verfallserscheinungen gesehen, die als symptomatisch für die Spätantike galten: als ein Konglomerat unverbundener Einzelerzählungen, eine barock anmutende Überfülle an Figuren, Handlungen und Schauplätzen, untermalt von einem Überangebot an lexikalischen Synonymen, als ein verworrener narrativer Knäuel, der eine Entwirrung unmöglich zu machen scheint. Der Umschwung, welcher ab der Mitte des 20. Jhs. innerhalb der

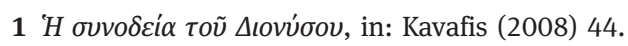

2 Vgl. Schmid u. Stählin (1980/61924) 970: „Daß die Sprache griechischer Poesie sich schließlich auch noch in den Dienst des Chaotischen und Maßlosen zwingen ließ, ist ein merkwürdiges, aber abstoßendes Schauspiel: ein brodelnder Hexenkessel, von dem sich die griechischen Musen und Chariten mit Abscheu abwenden“; sowie Fuhrmann (1967) 66: „,...] überdies hatten die landläufigen Maßstäbe einer klassizistischen Ästhetik Mühe, sich mit den Werken ins Einvernehmen zu setzen, zu deren wesentlichen Merkmalen Schwulst und grausig-häßliche Szenen gehören.“ 
Nonnos-Forschung einsetzte, brachte einen Paradigmenwechsel: Die Dionysiaka wurden nun in den Kontext der Zeit eingeordnet, die Dichtungen des Nonnos als Kondensat einer spätantiken Poetik aufgefasst. Die mit dem Prädikat typisch nonnianisch versehenen Eigenwilligkeiten der Dionysiaka bleiben jedoch oftmals nicht auf Nonnos beschränkt, sondern folgen einer allumfassenden, spätantiken „poetic koiné“, ${ }^{3}$ und sind auch in anderen Literaturen der Spätantike, griechischen wie lateinischen, zu beobachten.

\section{Enzyklopädische Gelehrsamkeit und (Inter-)Textualität}

Als Hauptcharakteristikum nonnianischer wie spätantiker Dichtung darf Pluralismus in jeglicher Hinsicht gelten. Sowohl auf der sprachlichen Mikro- als auch auf der kompositorischen Makroebene handelt es sich bei der Ampelos-Episode um ein poetisches Mosaik, das sein Wort- und Themenmaterial aus dem gesamten Fundus griechischer Dichtung schöpft. Das nonnianische und zugleich auch spätantike

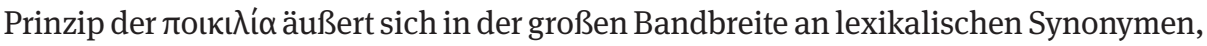
Stilfiguren und thematischen Variationen auf sämtlichen Ebenen der Dichtung. ${ }^{4} \mathrm{Ru}$ dolf Keydell hält fest, „daß das Hauptstreben des Dichters auf Variation des Ausdrucks gerichtet ist“ ${ }^{5}$ und Martin String konstatiert, „daß es ihm [sc. Nonnos] hier weniger auf die Aussage ankommt, als vielmehr auf die Möglichkeiten des Ausdrucks“. ${ }^{6}$ Im Zentrum dieser facettenreichen und mannigfaltigen Dichtung steht nicht etwa die logische Stringenz und narrative Geschlossenheit der Erzählung, sondern die kaleidoskopartige Präsentation unterschiedlicher sprachlicher und thematischer Möglichkeiten von Dichtung. Der höchste Grad an Buntheit in Stil und Präsentation findet sich in der paraphrastischen Bibelepik, zu der auch Nonnos' hexametrische Umsetzung des Johannes-Evangeliums zu rechnen ist. Dichter wie der Panopolitaner laufen hier zur Höchstform ihres poetischen Könnens auf, wenn sie Wörter des Ausgangstexts durch unzählige Synonyme im lexikalischen Bereich erweitern und so die Vorlage nach rhetorischem Usus in ihrer lyrisch-künstlerischen Intensität steigern, ja eine expressivdramatische Wirkung erzeugen. ${ }^{7}$ Durch die Einfügung von gelehrten Reminiszenzen an pagane Klassiker wie Homer im Griechischen und Vergil im Lateinischen wird die

3 Charlet (1988) 75.

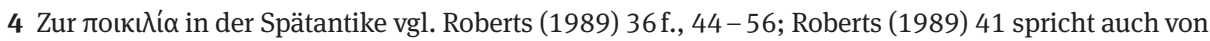
leptologia, einem bei Aquila Romanus, einem Rhetor des 3. Jhs. n. Chr., zu findenden Terminus, der das gesteigerte Interesse an kleinen und kleinsten Gestaltungselementen im spätantiken Kunstschaffen

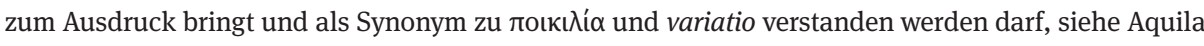
rhet. 2 Halm.

5 Keydell (1953) 17 (549).

6 String (1966) 108. - Dies gilt nicht nur für Nonnos, sondern auch für andere spätantike Dichter, etwa Prudentius, der ebenfalls mit etymologischen Wortspielen und ausgefeilter Stilistik arbeitet; vgl. Malamud (1989) $27-46$.

7 Vgl. Roberts (1985) 148-220 mit Beispielen aus der lateinischen Bibeldichtung. 
jeweilige Passage aus der Heiligen Schrift erweitert und stilistisch aufgewertet; ${ }^{8}$ entsprechend legen die in der Ampelos-Episode eingearbeiteten Ilias-Anklänge Zeugnis ab vom schöpferischen Umgang des Autors mit seinem Vorbild. ${ }^{9}$

Die Auseinandersetzung mit vergangenen, über Jahrhunderte tradierten literarischen Ausdrucksformen geht mit einem verstärkten Interesse an enzyklopädischer Gelehrsamkeit einher, ${ }^{10}$ die ausschließlich über das Medium Text sowie über die Prinzipien Textualität und Literarität funktioniert. Wenn im Rahmen der Ekphrasis der Tafeln Harmonias zu Beginn des 12. Buches der Dionysiaka die Schrift an sich zum Inhalt einer epischen Erzählung gemacht wird, so spiegelt dies die spätantike Freude am geschriebenen Wort wider (Nonn. D. 12,64-117). ${ }^{11}$ Nonnos bezieht nicht nur geläufige heidnische Mythen und antike literarische Genera in die Ampelos-Episode mit ein, sondern thematisiert zugleich auch die philologisch-mythographische Auseinandersetzung damit, eine besondere Technik, die spätestens seit dem Hellenismus zum festen Bestandteil der antiken Geistesgeschichte geworden ist und nicht nur in theoretischen Abhandlungen, sondern auch in literarischen Werken selbst diskutiert wird. Diese gelehrte Kommunikation mit den eigenen literarischen Wurzeln ist ein unverkennbares Charakteristikum nicht nur der Ampelos-Episode und der Dionysiaka, sondern des gesamten dichterischen Schaffens der Spätantike. ${ }^{12}$ Die voraussetzungsreichen lexikalischen und motivischen Anspielungen auf frühere literarische Gattungen und Werke werden allein durch die Präsentationsform Text für den Autor möglich und für das Publikum zu bewältigen.

Die Bezugnahme auf einen Hypotext oder gar eine ganze Hypotext-Gattung ist untrennbarer Bestandteil spätantiken dichterischen Schaffens. Für die Funktion von Intertextualität in den Dichtungen des Nonnos hält Robert Shorrock daher fest: „In the Dionysiaca things gain meaning primarily through their relationship to other things, and we are constantly invited to see one image or object in the light of another. "13 Das Weben eines Netzes von intertextuellen Anspielungen innerhalb der neuen Erzählung wird zum Credo spätantiker Dichtung. Wörtliche Übernahmen werden durch stilistische und motivische ergänzt, die Ausgangstexte und -genera werden zitiert, kommentiert, reorganisiert und in den neuen Kontext integriert. Ein spätantikes Gedicht ist nicht nur ein neuartiges literarisches Produkt, sondern stets auch eine Auseinandersetzung mit seinen Vorläufern, es kann bisweilen die Funktion eines philologischen Kommentars übernehmen und durch Kontrastimitation in einen künstlerischen Agon

8 Vgl. Roberts (1985) 157, 161f., 206.

9 Siehe Kap. 5.2.

10 Vgl. Döpp (1988) 36.

$11 \mathrm{Zu}$ Text und Übersetzung vgl. S. $190 \mathrm{f} ., 194 \mathrm{f}$.

12 Vgl. allgemein Döpp (1988) 27 und zu Dracontius in der lateinischen Literatur De Gaetano (2009)

370 f.: „Draconzio, tuttavia, non adotta passivamente il mito, ma lo varia, con risvolti ideologici finora inesplorati.“

13 Shorrock (2009) 101 f. - Zur Definition und Geschichte der Intertextualitätsforschung vgl. z B. Allen (2000). 
mit seinen Vorbildern treten: ${ }^{14}$ „Epic poets read and rewrote the past to fuse it with the present and to create a sustained narrative which was taken up and continued by successive poets. “15

\section{Fragmentierung und andere hellenistische Techniken}

Als typisch spätantik ist auch die Zersplitterung der Komposition in Einzelepisoden bei gleichzeitiger Wahrung ihrer Einheit zu werten. ${ }^{16}$ Traditionelle antike Literaturgattungen werden gleichsam seziert und in ihre Grundbestandteile zerlegt, sie werden in veränderte Kontexte gesetzt und erhalten neue Bedeutungsebenen zugewiesen. Klassische Gattungsgrenzen verschwimmen, die so entstehenden Bruchstellen im narrativen Erzählfluss sind Reflexionsflächen für das Verhältnis zwischen der spätantiken Dichtung zu ihren klassischen und hellenistischen Vorläuferinnen. Die Poetik der Fragmentierung kann dabei auch innerhalb der Erzählung selbst zum Thema gemacht werden. So sind Dionysos' Affinität zu Regellosigkeit sowie seine Unvereinbarkeit mit den Idealen des homerischen Epos auf metapoetischer Ebene ebenso als Spiegel nonnianisch-spätantiker Dichtungsprinzipien anzusehen wie die Zerstückelung des Dionysos-Zagreus durch die Titanen. ${ }^{17}$ Der Eindruck der Fragmentierung und Episodenhaftigkeit wird insbesondere durch die Integration unepischer Genera ins spätantike Epos erreicht: ${ }^{18}$ Rhetorische Gattungen wie Synkrisis, Enkomion, Ekphrasis und Ethopoiie finden dabei ebenso Eingang in die Dichtung wie biographischprosopographische Tendenzen. ${ }^{19}$ Vers-Enkomien auf Zeitgenossen mögen für Nonnos'

14 Vgl. Döpp (1988) 28, 44 f.; Ware (2012) 11.

15 Ware (2012) 31; vgl. auch Hadjittofi (2008) 118: „Nonnus keeps rearranging ,old“ meanings and cultural materials into new patterns, and although he is different from the bricoleur in that there is a design behind his creation (outlined in the prologue), as in bricolage the relation between the various elements (or clichés) is the main locus where meaning is created."

16 Vgl. Marrou (1937) 25: „[...] que le texte se soit présenté à l'esprit et à la réflexion non dans sa masse, dans son organisme, mais dans la série successive de ses éléments. On lisait Virgile non comme on contemple de haut un vaste paysage, mais comme on admire un collier de perles tenue entre les doigts, examinant chaque grain l'un après l'autre pour sa beauté propre“; vgl. auch Roberts (1989) 55 : "It was as though texts were put under a microscope, magnifying the constituent parts at the expense of the whole“; siehe auch Roberts (1985) 64f., 207.

17 Zur Thematik der Auflösung und Zerstückelung bei Claudian und Prudentius vgl. Malamud (1989) 47 - 78. - Der Neuplatonismus entwickelt eine eigene Theorie der Einheit eines literarischen Werkes, wonach dieses stets auf ein Handlungsziel, ein übergeordnetes, universelles Thema, hin ausgerichtet

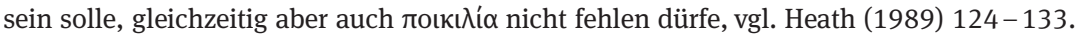

18 Zur Verarbeitung verschiedener Genera in der spätantiken Dichtung siehe Charlet (1988) $77 \mathrm{f}$.; Döpp (1988) 30 - 41; Picard (1990) 268; Ware (2012) 32 - 34; zur Verquickung der Genera bei Claudian siehe Müller G. M. (2011) 393 - 406; zu den Genera bei Ausonius vgl. Consolino (2003).

19 Vgl. Charlet (1988) 75; Ware (2012) 40. 
Lob des Ampelos, des Weines und des Dionysos ebenso Pate gestanden haben wie hellenistische Götterhymnen. ${ }^{20}$

Die Mélange unterschiedlicher Genera in ein und demselben Werk ist auch für die lateinische Dichtung der Spätantike signifikant:: ${ }^{21}$ Dracontius' Bibeldichtung De laudibus Dei entzieht sich ob der Synthese unterschiedlichster Gattungen - Enkomion, Götterhymnus, Epos, Lyrik und Rhetorik - einer eindeutigen Kategorisierung. ${ }^{22}$ Und selbst Dichtungen, die ihre Gattungszugehörigkeit deklarieren, integrieren eine Vielzahl genusfremder Motive und Techniken. So bieten etwa die Panegyriken des Sidonius Apollinaris ein breites Spektrum an unterschiedlichen literarischen Elementen: Die Panegyrik auf Avitus, den römischen Kaiser der Jahre 455-456 n. Chr., beginnt auf metapoetischer Ebene mit der Anrufung Apolls und der Musen (Sidon. carm. 7,1-16) und setzt auf kosmischer Ebene mit einer Götterversammlung sowie mit der geographischen Vermessung des römischen Imperiums in Gestalt eines Flusskatalogs fort (Sidon. carm. 7,17-44); in einer Prosopopoiie der Roma bietet der Dichter dem Leser eine tour de force durch die römische Geschichte (Sidon. carm. 7,45-122), außerdem lässt er Jupiter in einer Replik auf die Roma-Rede das Fatum als ein über allen Dingen stehendes göttliches Prinzip präsentieren (Sidon. carm. 7,123-138); und immer noch vor dem Beginn der eigentlichen Biographie des Avitus, die mit der Nennung seiner Vorfahren, seiner Erlebnisse in der Jugend, seines militärischen, politischen und diplomatischen Wirkens dem traditionellen Enkomion-Schema entspricht (Sidon. carm. 7,153-602), findet sich ein Elogium auf die Auvergne, Heimat des Avitus und Wirkungsstätte des Sidonius in seiner Funktion als Bischof von Clermont-Ferrand (Sidon. carm. 7,139-152).

Die poetischen Techniken und Stilprinzipien spätantiken Dichtens weisen zudem zahlreiche Ähnlichkeiten und Entsprechungen mit den hellenistischen auf: ${ }^{23}$ In beiden Fällen legen die Dichter ihren Schwerpunkt darauf, an vorhandene Traditionen anzuknüpfen. Hier wie dort stehen die Liebe zum Deskriptiven, wörtliche Übernahmen, Entlehnungen von Themen, Motiven und Rahmenhandlungen im Mittelpunkt ebenso

20 Zur Verarbeitung unterschiedlicher Genera in der Ampelos-Episode siehe Kap. 6.

21 Eine Debatte über die Gesetzmäßigkeiten lateinischer Poesie der Spätantike findet sich in Döpp (1988); Roberts (1989); Roberts (2007); Vergleichbares formuliert für die spätantike griechische und byzantinische Literatur Sergej Averincev in der russischen Originalausgabe Poétika rannevizantijskoj literatury von 1977 sowie in der 1988 unter dem Titel L'anima e lo specchio veröffentlichten italienischen Übersetzung, vgl. Averincev (1988); zu den ästhetischen Normen spätantiker Dichtung siehe auch Connor (1993) 257 f.; Agosti (2004-2005); Agosti (2006).

22 Vgl. De Gaetano (2009) 243, vgl. auch $124 \mathrm{f}$.

23 Siehe Kap. 5.3. - Zu den genannten Charakteristika hellenistischer Dichtung am Beispiel von Kallimachos und Ovid siehe van Tress (2004) 105-110, 120, 168, 180f., 189; zu hellenistischen Merkmalen der spätantiken Dichtung vgl. Charlet (1988); Döpp (1988) 35. Zur hellenistischen Formensprache in den Gedichten des Dracontius vgl. De Gaetano (2009) 123: „Se infatti alcuni elementi (i preziosismi stilistici, l'amore per i particolari scabrosi o patetici, lo sviluppo romanzesco delle vicende con attenzione agli aspetti psicologici e intimistici, la forte caratterizzazione retorico-scolastica di tutti i carmi) richiamano la poesia ellenistica [...].“ 
wie neue Kombinationen und narrative Innovationen, die eine Auflösung traditioneller Formensprachen bewirken und überkommene Lesegewohnheiten infrage stellen. Modifikationen von Mythen spielen mit der Erwartungshaltung des Publikums und machen das Kunstprodukt Dichtung als solches sichtbar. Die Mischung literarischer Genera problematisiert die Gattungsthematik und lässt Altes in neuem Licht erscheinen; durch die Auseinandersetzung der Dichtung mit sich selbst, ihren Motiven, Techniken und sprachlich-stilistischen Gestaltungsmitteln, werden bestehende Gattungsnormen hinterfragt und um neue, unkonventionelle Aspekte erweitert. Was charakteristisch für Ovid ist, darf auch als Grundprinzip nonnianisch-spätantiken Dichtens gelten: „[...] the poet borrowed, and changed freely from many different sources and genres in order to create his own tales."24 Ferner wurden auch Besonderheiten der hellenistischen Dichtung wie etwa die Tendenz zu Überzeichnung und gesteigertem Ausdruck, zu scharfen Kontrasten und Plastizität ähnlich wie bei Nonnos als barock tituliert. ${ }^{25}$ Wenn in der Spätantike im Bereich der Rhetorik von Zweiter oder gar Dritter Sophistik die Rede ist, ${ }^{26}$ so darf in der Dichtung mit Recht von einem Zweiten Hellenismus gesprochen werden. ${ }^{27}$

Die Auseinandersetzung mit mythischen exempla und epischen Topoi dokumentiert das gesteigerte Interesse an der literarischen Vergangenheit, ${ }^{28}$ die poetischhistorische Reflexion knüpft an vergangene Jahrhunderte an und versetzt diese durch besonders gelehrte Anspielungen in die spätantike Gegenwart. ${ }^{29}$ Aufgrund ihrer profunden sprachlichen und rhetorischen Bildung gehen auch die griechischen Kirchenväter frei und kreativ mit paganen Mythen um und passen diese in den jeweiligen christlichen Kontext ein. So arbeitet etwa Gregor von Nazianz in seine 39. Rede Eı $\iota \dot{\alpha}$ $\ddot{\alpha} y ı \alpha \Phi \tilde{\omega} \tau \alpha$ anlässlich des christlichen Theophanie-Festes einen umfangreichen Katalog heidnischer Götter und Heroen ein, die gleichsam als negative Kontrastbilder zum eigentlichen Anlass des Festes, der Taufe Jesu, dienen. Unter den genannten

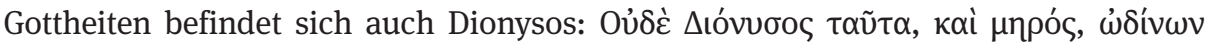

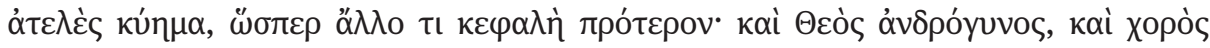

24 Van Tress (2004) 159.

25 Vgl. Hughes Fowler (1989) 32 - 43. - Neben Nonnos werden auch andere spätantike Autoren mit dem Prädikat barock versehen, vgl. Connor (1993) 242 über Claudius Claudianus: „the full-blown baroque of his description“; zu Apuleius vgl. Picard (1990) 266-273.

26 Zur Rhetorik in der Spätantike und im frühen Byzanz sowie zur Dritten Sophistik siehe Kustas (1971); Agosti (2006) 35 Anm. 1 mit weiterführenden Literaturangaben; Fowler R. (2014).

27 Von einer klassizistischen Rückbesinnung der Spätantike auf frühere Phasen der Literatur spricht Connor (1993) 257 f.; vgl. auch Brown (1980) 22 f.: „To the Late Antique world, the classical tradition was not what it has become for us, a distant ideal that could be ,revived" or imitated at will: it was simply the only tradition that was known to work“; siehe außerdem Ševčenko (1980).

28 Vgl. Basson (1996) 276: „By virtue of their class and education, many late antique poets and writers were imbued with a deep reverence for the past and its literary forms, yet in response to the changes that were shaking their world, they were often compelled to venture into uncharted areas, to pioneer new possibilities, and to traverse existing boundaries“; Kaldellis (2007) 173-180; Ware (2012) 43 - 45. 29 Vgl. Döpp (1988) 27. 


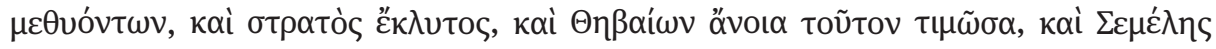

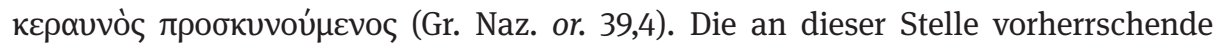
polemisierende Funktion des Mythos weicht anderswo im Werk Gregors einer durchaus positiven Einstellung gegenüber paganen Traditionen, die Christen als Bildungsgrundlage empfohlen werden (vgl. Gr. Naz. carm. 2. 2 [poem.], 4 und 6). ${ }^{30}$ Die Rezeption antiker Mythen operiert mit der Kommunikationslinie zwischen Autor und Leser. ${ }^{31}$ Im Spiel mit dem gebildeten spätantiken Publikum wird - je nach Textsorte und Anlass - der pagane Mythos entweder als negative Antithese christlichen Inhalten gegenübergestellt, oder ist, nun jeglicher religiöser Bedeutung entledigt, als bloßes stilistisches Ornament und literarisches Versatzstück für die Angehörigen der Bildungselite, ungeachtet ihrer eigenen Konfession, frei zur Rezeption. ${ }^{32}$

\section{Visualität und Bildhaftigkeit}

In seinem für das Verständnis der spätantiken Dichtung wegweisenden Buch bringt Michael Roberts einen wesentlichen Aspekt der poetischen Ästhetik dieser Zeit auf den Punkt: „The elements of a text were understood chromatically, described as multicolored flowers or jewels. The art of the poet was akin to that of the jeweler - to manipulate brilliant pieces [...] and to throw them into relief by effects of contrast and juxtaposition. The poet strives for an impression equivalent to that of a flower-covered meadow in spring. “33 Die Vorliebe der Kaiserzeit für alles Bildhafte spiegelt sich in der Korrelation von Verbalem und Visuellem in der spätantiken Dichtung wider. ${ }^{34}$ Gianfranco Agosti spricht von einer regelrechten „spettacolarizzazione“, einem „mondo visuale $^{\text {“35 }}$ und einer Ästhetik der Digression. ${ }^{36}$

Ein spätantikes Stück Dichtung ist nicht nur auf der sprachlichen Mikroebene, sondern auch in seiner narrativen Anlage im Großen mit zeitgenössischen Mosaiken vergleichbar. ${ }^{37}$ Wie in der Mosaikkunst gruppieren sich verschiedene, in sich geschlossene Einzelszenen um eine zentrale Figur oder um ein Leitthema. Gleichsam wie durch eine Themenausstellung geleitet der Dichter den Rezipienten von einer Szene zur nächsten, das Lesen eines Textes ist gleichzusetzen mit dem Betrachten eines

30 Zum Umgang mit paganen Mythen und biblischen exempla durch Gregor von Nazianz vgl. Pyykkö (1991) und Demoen (1996); zu Nonnos und Gregor siehe Haidacher (1949) 76 - 80; D’Ippolito (1994). 31 Zur Kommunikation spätantiker Dichtung mit dem Publikum vgl. Malamud (1989) 38.

32 Vgl. Döpp (1988) 29, 33 f.; Kaldellis (2007) 178: „A professor could mock the Greek gods in a Christian oration and then describe the luxurious beauty of Aphrodite to show off his skill in an ekphrasis.“

33 Roberts (1989) 55.

34 Vgl. Roberts (1985) 205 f.; Francis (2009) 290.

35 Agosti (2004-2005) 352; vgl. auch Agosti (2014).

36 Vgl. Agosti (1995); Charlet (1997) 495: „[...] denn die spätantike Dichtung ist eine visuelle Kunst, sie stellt dar im Spiel der Lichter und Farben [...].“

37 Vgl. Roberts (1989) 66-121; Agosti (2004-2005) 355f.; Ware (2012) 34-36. 
Bildes. ${ }^{38}$ Michael Roberts exemplifiziert diese Beobachtungen an ausgewählten Beispielen der Mosaikkunst, etwa an einer Jagdszene aus Antiochia aus der Mitte des 5. Jhs. n. Chr. ${ }^{39}$ Die verschiedenen Szenen gruppieren sich in konzentrischen Kreisen um die zentrale Büste der Personifikation der Megalopsychia, die Einzelszenen fügen sich durch das gemeinsame Thema Jagd zu einem thematischen und kompositionellen Ganzen. ${ }^{40}$

Mit der Aufgliederung in Einzelbilder und -episoden verfolgen spätantike Dichter und bildende Künstler eine Art Patchwork-Technik, ${ }^{41}$ die unterschiedliche Mythen um ein gemeinsames Oberthema gruppiert. Bildhaftigkeit im Ausdruck findet sich in sämtlichen poetischen Genera, in ihrer reinsten Form als selbstständige Literaturgattung, der Ekphrasis, erfreut sie sich größter Beliebtheit. Als Beispiel sei ein Gedicht des Sidonius Apollinaris genannt, eine literarische Ekphrasis auf das private Domizil des Pontius Leontius, eines lokalen Gönners und Kunstmäzens in Aquitanien, mit Beschreibungen der Götter Bacchus, Apollon und ihrer Gefolgschaften sowie dem architektonischen Gesamtensemble der Residenz (Sidon. epist. [carm. 22] 6): In dem Begleitbrief an Pontius Leontius rechtfertigt Sidonius die Kategorisierung seines Gedichts als Epigramm, obwohl dessen Umfang diesem literarischen Genus eigentlich nicht entspreche. Auch hier manifestiert sich die in der Spätantike geläufige Auseinandersetzung mit den Gattungsdefinitionen; Ekphrasen sind dabei nie bloß Ornament, sondern stets Handlungsträger und beziehen den Leser als aktiven Part bei der Rezeption der Dichtung mit ein. ${ }^{42}$

Die gesteigerte Bildhaftigkeit wird auch in Arbeiten zu Nonnos hervorgehoben, das nonnianische Epos wird als „tapiz multicolor“43, als „un complejo mosaico tardío o una tela copta“44, „epic tableau“45 ${ }^{\text {“4 }}$ und „frozen artistic image“ ${ }^{\text {“46 }}$ charakterisiert. Ebenso wird die Mosaikhaftigkeit in der Komposition der Dionysiaka wiederholt festgehalten: „Nonnian actions are not casually connected (propter hoc), but are, in one of his own favorite terms, simply geitones, neighbors of one another, as in a tapestry or mosaic. “47 Die narrative Funktion der Bilder-Sprache wird insbesondere in der Ampelos-Episode sichtbar, welche eine in sich geschlossene, narrative Einheit innerhalb der Dionysiaka bildet und sich gleichzeitig auch selbst aus kleineren Erzähleinheiten konstituiert. ${ }^{48}$ Der bedeutende Stellenwert, den die Bildhaftigkeit in der Poesie des Nonnos einnimmt, wird insbesondere aus einer Stelle in Buch 12 kenntlich:

38 Vgl. Malamud (1989) 40.

39 Vgl. Roberts (1989) 82 Abb. 4.

40 Vgl. Cimok (2000) 251- 275.

41 Vgl. Veyne (2009) 44.

42 Vgl. Malamud (1989) 57.

43 García-Gasco (2010) 3.

44 Hernández de la Fuente (2008) 209.

45 Ware (2012) 36.

46 Ware (2012) 39.

47 Braden (1974) 863; vgl. außerdem Keydell (1936) 910; Vian (1976) 90; Shorrock (2001) 17 - 23.

48 Siehe die Zusammenstellung der Einzelszenen der Ampelos-Episode auf S. $199 \mathrm{f}$. 
Auf einer der Ampelos-Handlung übergeordneten Ebene schreitet die Herbsthore im Palast des Helios die vier Tafeln der Harmonia ab, um Informationen über den Verbleib der Weinrebe zu erlangen. Die Szene darf als metapoetischer Spiegel der Prinzipien nonnianischen und spätantiken Dichtens verstanden werden; so wie die Hore von einer Bildtafel zur nächsten flaniert, bekommt der Rezipient spätantiker Dichtung einen Mythos präsentiert, der sich in Einzelszenen aufgliedert, welche über zahlreiche sprachliche und thematische Entsprechungen sowohl untereinander als auch in Bezug auf den Haupt-Mythos korrelieren. Nonnos' bilderreiche Sprache verdichtet sich in der Horen-Szene zu einer Bilderschau, die selbst zum Hauptthema der Dichtung wird.

\section{Der Umgang mit der Zeit und ihre Personifikationen}

Die narrative Kategorie Zeit ist in spätantiken literarischen Werken meist nicht mit antik-heidnischem Maßstab zu messen. Die Auffassung von Zeit als linear-chronologischem Kontinuum tritt hinter eine allenthalben $\mathrm{zu}$ beobachtende Tendenz zur Atemporalität zurück, ${ }^{49}$ ein Phänomen, das nicht nur in der Literatur, sondern auch in zahlreichen Bereichen der spätantiken Kultur und Gesellschaft begegnet. So verstand sich etwa das spätantike Kaisertum als permanente Erneuerung und Restauration, der Herrscher nicht als gegenwärtiger, sondern als ein zeitloser und dauerhafter; ${ }^{50}$ epigraphische Zeugnisse, wie sie auch Nonnos mit den Tafeln der Harmonia in der Ampelos-Episode entwirft, werden keineswegs als Dokumente einer weit zurückliegenden Ära aufgefasst, sondern als etwas Gegenwärtiges und gleichzeitig Zukunftsweisendes. ${ }^{51}$ Die chronologischen Unstimmigkeiten in literarischen Werken wie den Dionysiaka oder auch in Produkten der spätantiken bildenden Kunst bilden ein immerwährendes, transtemporales ${ }^{52}$ Zeitkontinuum ab, das mit der Vorstellung der zyklischen Wiederkehr von Persönlichkeiten, Themen und Grundprinzipien operiert. ${ }^{53}$

Die Zeitlosigkeit wird innerhalb der Dionysiaka in der Erzählung um die Genese des Weines augenscheinlich, die von Zeus im 7. Buch angekündigt, in der Gestalt des Ampelos verkörpert und schließlich - nach zahlreichen subtilen Anspielungen auf die neue Pflanze - am Ende des 12. Buches realisiert wird. Die narrative Technik von Ankündigung und Ausführung in Gestalt von Omina und Prophezeiungen trägt soteriologische Züge, die insbesondere auch für das spätantike Christentum Relevanz zeigen, das die Universalität, zeitlose Absolutheit und Wahrheit ihres Gottes durch christliche Prophetien und pagane exempla herausarbeiten will. ${ }^{54}$ Bei der Vereinigung

49 Vgl. Springer (1988) 96-100; Gutteridge (2006); siehe auch S. $210 \mathrm{f}$.

50 Vgl. Gutteridge (2006) 578.

51 Vgl. Gutteridge (2006) $585 \mathrm{f}$.

52 Vgl. Gutteridge (2006) 587: „transtemporal significance“.

53 Vgl. Malamud (1989) 111; Gutteridge (2006) 588-590; Ware (2012) 101-116.

54 Vgl. Roberts (1985) 180f.; Kennedy (1999) 138, 140 f.; Gutteridge (2006) 587; Spira (2007). - Die Atemporalität des christlichen Gottes thematisiert auch Dracontius: [...] tu temporis expers. / Numquid 
von Vergangenheit, Gegenwart und Zukunft in einer Erzählung handelt es sich nicht etwa um ein christliches Spezifikum, heidnische Werke wie die Dionysiaka oder die Dichtungen des Claudius Claudianus arbeiten gleichfalls mit Vorverweisen durch Omina. ${ }^{55}$ Der spätantike Dichter, sei er nun Christ oder Heide, wird zum Propheten. ${ }^{56}$

Das Konzept der periodischen Wiederkehr findet sich auch in Personifikationen der Zeit wieder. ${ }^{57}$ Schon Ovid zeigt in den Metamorphosen die Horen im Palast des Helios, den Herbst mit Trauben als Attribut (Ov. met. 2,25-30), und auch bei Claudian tritt ähnlich wie in den Dionysiaka Aion als Ordner des Zeit- und Weltgeschehens auf. ${ }^{58}$ Zum gemeinsamen Repertoire der Spätantike sind zudem Personifikationen von abstrakten Begriffen zu rechnen, wie sie etwa Ate und Atropos in der Ampelos-Episode darstellen:59 Der Auftritt der Moire Atropos im 12. Buch der Dionysiaka ist in seiner Art außergewöhnlich, jedoch nicht gänzlich beispiellos; in einem Epithalamium des Sidonius Apollinaris (Sidon. carm. 15,200) wird Atropos namentlich genannt, und bei Quintus Smyrnaeus kommt der Aisa/Moira insofern eine bedeutende Rolle zu, als sie ähnlich wie Aion in den Dionysiaka - über Zeus und den anderen Göttern steht. ${ }^{60}$ Auch in den Dichtungen des Dracontius nehmen die fata eine alles überragende und bestimmende Rolle an. ${ }^{61}$ Personifikationen als handelnde Figuren in einer Erzählung haben in Prudentius' Psychomachia, dem Kampf der Tugenden gegen die Laster, ein prominentes Beispiel, in dem insgesamt sechs Paare und eine Trias in einem „Seelenkampf “ miteinander ringen. Die Popularität der Moiren ist auch in der spätantiken bildenden Kunst zu beobachten, etwa in einer Darstellung der Schicksalsgöttinnen, von denen jeweils eine verunglückte mythische Figuren (Phaethon, Daidalos und Ikaros, Meleager) beklagt und deren Schicksal durch Vorlesen eines Schriftstückes verkündet. ${ }^{62}$ Beide künstlerischen Medien, Bild und Text, schöpfen aus demselben Formenrepertoire und bringen dieselben Techniken zur Anwendung. Der Auftritt der Atropos und der Horen in der Ampelos-Episode ist im Lichte dieser ästhetischen Stilprinzipien der Spätantike zu lesen, die für Literatur und bildende Kunst gleichermaßen Gültigkeit haben.

habes, Deus, ante tuum vel post cadit in te? (Drac. laud. dei 3,739f.). - Ein vergleichbares Konzept von Zeitlichkeit wendet Nonnos in der Paraphrase an: In Nonn. P. 13,1-16 dient die Zeitangabe des Pessach-Festes als Vorankündigung der Auferstehung Jesu, vgl. Greco (2004) 15 -17.

$55 \mathrm{Zu}$ Claudian vgl. Ware (2012) 52.

56 Vgl. Roberts (1985) 179f.: „The poet now speaks as a praedicator rather than a narrator.“

57 Personifikationen von abstrakten Begriffen jeglicher Art erfreuen sich auch in der spätantiken Kunst großer Beliebtheit, was die zahlreichen Werke der Mosaikkunst, z. B. die verschiedenen Personifikationen auf antiochenischen Mosaiken, belegen, vgl. Cimok (2000) 232-237, $251 \mathrm{f}$.

58 Vgl. Ware (2012) $102 \mathrm{f} ., 115 \mathrm{f}$.

59 Vgl. Ware (2012) 49.

60 Vgl. Maciver (2012) 114-122.

61 Vgl. De Gaetano (2009) 149-157.

62 Vgl. Giannoulis (2010) Tafel 10 Abb. 26 und 17, Tafel 11 Abb. 29. 


\section{Kosmologie und Metapoetik}

Personifikationen des Kosmos wie Helios, die Horen und die Schicksalsgöttinnen dienen als ordnende Kompositionselemente und als Rahmen für den oftmals verwickelten Gang der Handlung. In enger Verbindung damit steht der starke Kontrast zwischen Ordnung und Chaos, Licht und Dunkel, Gut und Böse, den die spätantike Ästhetik favorisiert. ${ }^{63}$ Nicht nur die bei Prudentius gegeneinander kämpfenden Tugenden, sondern auch andere Gottheiten und göttliche Prinzipien werden in Dichtungen der Spätantike zu Sinnbildern narrativer Gliederung, so etwa Apollo und Iustitia, die Frieden und ein Goldenes Zeitalter repräsentieren, ${ }^{64}$ oder analog dazu Dike in den Dionysiaka, welche die neue dionysische Ära einläutet. Diese kosmologische Dimension ist nicht nur wesentliches Strukturelement spätantiker Dichtungen, sondern bietet dem Autor auch Gelegenheit zur Reflexion seiner Erzählung auf übergeordneter Ebene. ${ }^{65}$ Von den mythischen Gegenpaaren, die Nonnos in den Dionysiaka aufeinandertreffen lässt - Zeus und Typhon, Zagreus und die Titanen, Dionysos und Deriades -, tragen letztlich niemals die Usurpatoren, sondern stets die rechtmäßigen Machthaber den Sieg davon, die von den höheren kosmischen Mächten festgesetzte Ordnung wird so wiederhergestellt.

In enger Verbindung mit derartigen narrativen Dispositionen steht die Auseinandersetzung des spätantiken Dichters mit seinen Vorgängern. Die Reflexion lange währender Traditionen antiken Literaturschaffens, die Wiederaufnahme und Neuinterpretation von Topoi und Figurentypen sind ebenso Teil dieses künstlerischen Dialogs mit der Vergangenheit wie die Mischung von Gattungen und die Tendenz zum enzyklopädischen Sammeln von Wissen und kulturellen Erfahrungswerten. Das Abgleichen von überkommenen und neuartigen poetischen Darstellungsformen ist Teil des agonalen Prinzips und der obligaten Selbstreflexion des spätantiken Literaten. Viele der in den Dionysiaka anzutreffenden Szenen zeigen auch metapoetische Relevanz wie etwa die Konfrontation zwischen Zeus und Typhon, welche gleichzeitig auch eine Auseinandersetzung mit den Möglichkeiten und Unmöglichkeiten des Dichtens ist.

Griechische Dichtung hat von Homer bis in die römische Kaiserzeit eine lange Wegstrecke hinter sich gelegt, als deren End- und Kumulationspunkt die Dionysiaka sämtliche literarische Ausdrucksformen antiker Gräzität durch die vorgenommenen Innovationen für kommende Dichtergenerationen festhalten und fruchtbar machen.

63 Vgl.Ware (2012) 50f., 117 - 170 über Claudian, bes. 124: „The tension and balance between good and evil, furor and concordia, Heaven and Hell, pervade the poem.“

64 Vgl. Ware (2012) 201.

65 Vgl. Malamud (1989) 72 - 75; Ware (2012) 128-134; zur Kosmologie in der Ampelos-Episode vgl. Kap. 7.3. 


\subsection{Das soziokulturelle Umfeld}

\section{Von Identität und Religion - Die hellenische Bildungselite}

Die Anerkennung der Dionysiaka und anderer dichterischer Werke der Spätantike als autonome literarische Produkte wurde mit dem Aufblühen der Spätantike-Forschung ab der zweiten Hälfte des 20. Jhs. vorbereitet und eingeläutet. Literarisches Wirken wie das des Nonnos wird seitdem dem soziokulturellen Umfeld der spätantiken Bildungsschicht des östlichen Mittelmeerraums unterstellt, die eine erschöpfende Ausbildung in den Bereichen der griechischen Grammatik, Literatur und Rhetorik genoss und sich als Erbin der hellenischen Kultur verstand: „It is the idea of a community of men educated in the rhetorical tradition, a community not of birth nor of wealth but of education. Associated with it are the moral virtues of humanity and pity, and the duty of mutual help between members. [...] Thus the Hellenes formed an ideal community which bore some resemblance to the Christian church." ${ }^{66}$ Die Zugehörigkeit zu dieser Gruppe der Hellenen ist nicht etwa durch Ethnie oder Konfession bedingt, sondern vielmehr durch die Teilhabe an einem konservativen Bildungsprogramm, das durch eine bemerkenswerte Langlebigkeit und Permanenz mythischer, historischer und literarischer Traditionen geprägt ist. ${ }^{67}$ Ausdrucksmedien dieses Selbstverständnisses sind die Literatur und die bildende Kunst, die das antike Griechenland in die Spätantike versetzen und mit den veränderten kulturellen Gegebenheiten des zeitgenössischen Kontexts verschmelzen. ${ }^{68}$ Dabei handelt es sich nicht um eine Renaissance der klassischen Antike, sondern um die kontinuierliche Weiterführung des heidnischen Bildungsgutes.

Prägend für die hellenische Bildungselite ist der kontinuierliche Austausch zwischen Heiden- und Christentum, sie definiert sich über den gemeinsamen Bildungshintergrund, die $\pi \alpha \mathrm{s} \delta \varepsilon^{\prime} \alpha$, und nicht etwa über die Zugehörigkeit zu einer bestimmten religiösen Konfession. ${ }^{69}$ Die Teilhabe an der klassischen Literatur und dem kulturellen Formenschatz vergangener Jahrhunderte legt die Basis für eine „koiné of Mediterranean religious experience“"70, für eine heidnisch-christliche „biculturalité“"71, die das säkulare Geistesleben des 5. Jhs. n. Chr. nachhaltig prägt. Antike Mythen, konven-

66 Liebeschuetz (1972) 16; vgl. auch Brown (1992) 35 - 70; Agosti (2014a) 298 f.

67 Vgl. Swain (1996); Liebeschuetz (2001) 223 f.; Whitmarsh (2001); Cameron Alan (2004) 344 - 349;

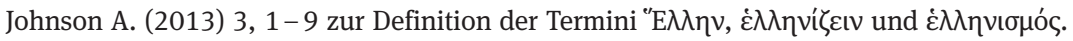

68 Vgl. Whitmarsh (2001a) 273: „The extant literature of the period was in this day the fundamental vehicle of self-definition for the urban elites of the eastern Empire“, und 305: „[...] cultural identity as manifested in literature is inseparable from literary strategy.“

69 Zur Interaktion von Heiden- und Christentum in der Spätantike vgl. Downey (1963) 195 - 198; Fuhrmann (1967) 72, 76; Fontaine (1982); Liebeschuetz (1990) 150, 250 f.; Trombley (1995) Bd. 1, 188-245 und Bd. 2, 1-20, 52-73; Brown (1998) 24-27, 58f.; Salzman (2008); Cameron Alan (2011) 7 f.; Cameron Averil (2012) $72-75$.

70 Brown (1978) 97.

71 Fournet (2003) 521. 
tionelle Formensprachen und literarische Autoritäten dienen im Sinne einer gemeinsamen Erinnerungskultur als „vehicles for rememberence ${ }^{\text {“72 }}$ und formen das Selbstverständnis der spätantiken Hellenen. Dabei entbehren mythisch-religiöse Themen jeglicher religiöser Bedeutung, das gelehrte literarische Spiel mit dem Vermächtnis Griechenlands steht im Mittelpunkt eines gebildeten Dialogs innerhalb dieses gesellschaftlichen Netzwerks. Die heidnischen Götter sind nicht mehr in ausschließlich religiösem Zusammenhang zu sehen, sondern werden zu Dekorationsmotiven, zu willkommenen Versatzstücken der bildenden Kunst und Literatur, die von allen Angehörigen der Bildungselite als Embleme hellenischer Kultur dechiffriert werden können. ${ }^{73}$

In ebendiesen soziokulturellen Kontext sind auch die Dionysiaka einzuordnen. Klassische Autoren wie Homer, Pindar oder Kallimachos sowie die Beherrschung sämtlicher literarischer Konventionen bilden das Fundament für die eigene innovative Schaffenskraft des Dichters. Sein Zielpublikum ist ebendiese hellenische Oberschicht des Ostens, die aufgrund ihres Bildungsweges mit der griechischen Vergangenheit aufs Engste vertraut ist. ${ }^{74}$

\section{Von der Peripherie ins Zentrum - Hellenen in Ägypten}

Auch Ägypten, die Heimat des Nonnos, war in der Spätantike ein Zentrum dieser

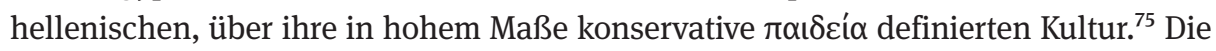
Griechen des östlichen Mittelmeerraums erhalten ihre höhere Bildung in regionalen und überregionalen städtischen Zentren wie Panopolis, Alexandria oder Beirut. Die über Jahrhunderte tonangebende Stadt Athen verliert zunehmend ihre Funktion als identifikationsstiftender Kreuzungspunkt, das kulturelle Kerngebiet der Hellenen verlagert sich in periphere Gebiete des römischen Reiches. Die einschneidenden politischen Veränderungen in der Spätantike, die Ablösung Roms als Hauptstadt durch eine Vielzahl an Verwaltungszentren, gehen mit der geographischen Neuorientierung ihrer Bewohner einher. ${ }^{76}$ Für die Hellenen des Ostens zieht die Verlagerung des kulturellen Mittelpunkts weg von Athen und dem griechischen Mutterland hin in die Städte des Ostens einen Perspektivenwechsel nach sich. Mit Griechisch als ihrer Muttersprache und ihrem Bildungshintergrund verstehen sie sich selbst als Repräsentanten eines neuen, alten Hellenentums; sie führen ihre Existenz auf das klassische Athen zurück und setzen sich mit ihren Vorgängern literarisch auseinander, definieren sich gleichzeitig aber auch durch spezifisch spätantike Komponenten. Literarische

72 Koortbojian (1995) 114.

73 Vgl. Haas (2004) 217, 229.

74 Vgl. Liebeschuetz (2001) 234; Frangoulis (2000) 150: „[...] un morceau littéraire composé à partir de sources diverses pour un lecteur érudit.“

75 Vgl. Swain (1996) 65-100; Bingen (2007) 242-248; Benaissa (2012) 526-535.

76 Vgl. Brown (1995) $66 \mathrm{f} . ;$ Chuvin (1994); Ware (2012) $67 \mathrm{f}$. 
Werke des 5. Jhs. n. Chr. sind nicht ausschließlich retrospektive Hinwendungen zur klassischen Antike, sondern stets auch eine Positionierung der philhellenischen Elite in einer Welt, in der das Christentum sich bereits etabliert hat. Die Inhalte der paganen Antike, die von dieser Elite übernommen werden, sind völlig ungeachtet der Glaubenszugehörigkeit des Einzelnen eine kulturelle Kennmarke, die von den Theologen nicht mehr angefeindet werden muss, da sie bereits einer mythischen Vergangenheit zuzurechnen und frei für literarische Nutzung ist.

\section{Mythen und Orte der Erinnerung}

Die Orientierung an der klassischen griechischen Kultur wird in den Dionysiaka insbesondere an solchen Stellen kenntlich, wo griechische Orte und Mythen in die unmittelbare Erzählebene mit einbezogen werden. ${ }^{77}$ Die Ampelos-Episode selbst rekurriert in Nonn. D. 12,147-153 auf eine für das klassische Griechenland charakteristische Institution: die attische Tragödie. ${ }^{78}$ Der Vorausblick auf die zu Ehren des Dionysos dargebrachten kultischen Darbietungen mit Musik- und Tanzbegleitung, den Nonnos im Zusammenhang mit der Prophezeiung von Ampelos' glanzvoller Zukunft gewährt, geschieht von einer altehrwürdigen, mythischen Urzeit aus, ein fester Bestandteil des kulturellen Selbstverständnisses der Hellenen in klassischer Zeit wird im geschilderten Mythos vorweggenommen. Die Tatsache, dass es sich bei den Dionysiaka um ein Werk der spätantiken römischen Kaiserzeit handelt, spricht dem geschilderten Festakt für den Weingott eine universelle und diachrone Relevanz zu: Der Dichter konstruiert eine direkte Verbindungslinie von den Anfängen des heidnischen Mythos über kulturgeschichtliche Realitäten des 5. Jhs. v. Chr. bis in seine eigene Zeit. Die griechische Oberschicht im spätantiken Ägypten des 5. Jhs. n. Chr. versteht sich als Träger dieser mehr als ein Jahrtausend alten kulturellen Traditionen, als Fortschreiber hellenischer Geschichte und Literatur.

An zahlreichen weiteren Stellen in den Dionysiaka greift Nonnos auf Elemente der klassischen griechischen Kultur zurück. Innerhalb der größtmöglichen geographischtopographischen Ausdehnung, die das Epos bietet, fokussiert der Dichter seine Erzählung auch auf Landschaften, Landmarken und Örtlichkeiten, die er zu Schauplätzen des Geschehens macht. Eine solche Landschaft ist Griechenland, das durch seine Geschichte und die in ihm angesiedelten Mythen kulturell vorbelastet ist. Hellas ist für Nonnos das Stammland der Mythen ( $\mu \nu \theta$ отóкоv $\pi \lambda$ ćov $^{*} \mathrm{E} \lambda \lambda \alpha \dot{\alpha} \delta \alpha$ [Nonn. D. 1,385])

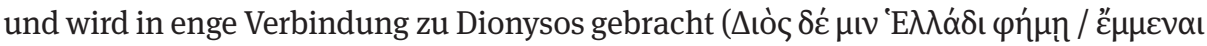
$\varepsilon ’ \pi \lambda \alpha \sigma \varepsilon \mu \tilde{0} \theta o \varsigma$, „Dass er [sc. Dionysos] von Zeus abstammt, ist ein Mythos der grie-

77 Vgl. Hadjittofi (2011) 31: „In many ways the Dionysiaca is a celebration of Greek culture.“ 78 Vgl. dazu S. $147-150$. 


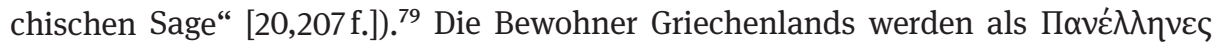
bezeichnet und somit als kulturelle Einheit aufgefasst (Nonn. D. 4,252). In den Dionysiaka werden mythische und historische Traditionen in Verbindung mit Griechenland sichtbar, das Mutterland der hellenischen Kultur ist gleichsam der Container für hellenischen Mythos und Geschichte. ${ }^{80}$

\section{Die Schule von Gaza und andere Erben des Nonnos}

Ein weiterer Schauplatz dieser spätantiken Bildungsgesellschaft ist Gaza in Palästina, das noch im 6. Jh. n. Chr. die klassizistischen Tendenzen der spätantiken Literatur fortführt. ${ }^{81}$ Jüngste Untersuchungen zum Einfluss des Nonnos auf die Dichtungen der Schule von Gaza zeigen erste Ergebnisse und bieten zahlreiche Anknüpfungspunkte für weitere vielversprechende Forschungen im Bereich der Spätantike. ${ }^{82}$ Dabei wird nicht nur Nonnos' Sprache und Metrik etwa von Johannes von Gaza in kreativer Weise rezipiert, beide Seiten teilen die gleiche poetische Motiv- und Formensprache, wie sich auch anhand der Ampelos-Episode illustrieren lässt. Ein Leitthema und Schlüssel zum Verständnis der Bücher 10, 11 und 12 der Dionysiaka ist die allenthalben anzutreffende Vegetationsmotivik: Schon zu Beginn der Ampelos-Episode lassen die Horen anlässlich des Bades des Dionysos Rosen und Lilien sprießen (Nonn. D. 10,171f.). Die Rose, Attribut der Liebesgöttin Aphrodite, unterstreicht Ampelos' Schönheit und nimmt die erotische Literatur in die Ampelos-Episode mit herein (Nonn. D. 10,190). Ebenfalls dieser Thematik ist der Kranz aus Narzissen und Hyazinthen zuzurechnen, den Eros als Zeichen der Verbundenheit von Dionysos und Ampelos flicht (Nonn. $D$. 10,336 - 338). Die Narzisse und die Hyazinthe greifen zugleich das Todesschicksal des Satyrn auf, der in dem folgenschweren Spiel mit dem Stier sein Leben verliert, unmittelbar vor dem Unglücksfall schmückt Ampelos das Tier mit frischen Blumen

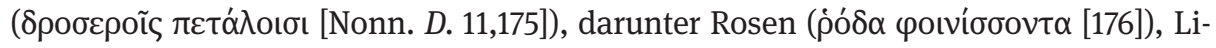

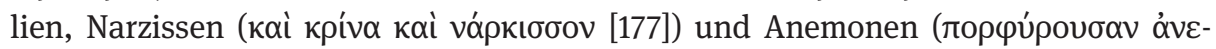
$\mu \omega ́ v \eta v$ [178]). Nach dem Tod seines Lieblings streut Dionysos Rosen- und Anemo-

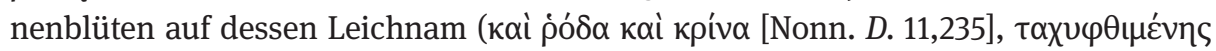

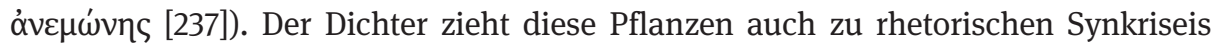
heran, insbesondere in der die Episode beschließenden Rede des Dionysos (Nonn. $D$.

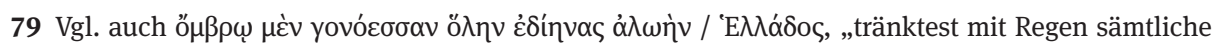
Gärten von Hellas zu reicher Ernte“ (Nonn. D. 22,278f.), wo Dionysos, ähnlich wie sein Vater Zeus, als Regenbringer charakterisiert wird.

80 Für eine Analyse des Griechenland-Bildes, wie es in den nonnianischen Gedichten greifbar wird, vgl. Kröll (2016).

81 Zur kulturellen Situation im spätantiken Gaza sowie zur sog. Schule von Gaza vgl. Downey (1958); Bitton-Ashkelony u. Kofsky (2004); Saliou (2005); Bitton-Ashkelony u. Kofsky (2006); Di Segni (2007); Jones Ch. (2014) 135-137; Lauritzen (2014).

82 Vgl. De Stefani (2014); Lauritzen (2014). 
12,207-291). ${ }^{83}$ Ziel und Endpunkt ist stets der Wein, der neben seiner vielseitigen Verwendung vor allem Sorgen lösende Wirkung verspricht.

Enkomien und Psogoi auf Pflanzen gehören nicht nur bei Nonnos zur gängigen rhetorischen Praxis, sondern auch in den Dichtungen und Prosawerken der Gazener. Die Motive der Rose und des Aufblühens der Vegetation im Frühling finden sich beispielsweise in anakreonteischen Gedichten des Johannes sowie in Prosa-Deklamationen des Prokopios von Gaza wieder. ${ }^{84}$ Auch Musaios orientiert sich in seinem Kurzepos Hero und Leander an nonnianischer Diktion; die Präsentation der Titelheldin rezipiert durch vielerlei lexikalische Übernahmen und motivische Anlehnungen das Ampelos-Porträt (Musae. 55-66 Nonn. D. 10,175-192): Ampelos' und Heros

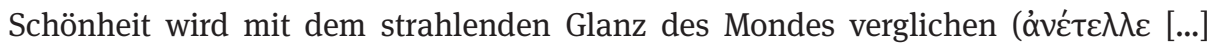
$\Sigma \varepsilon \lambda \eta \dot{v \eta ~[N o n n . ~ D . ~ 10,185 ~ u n d ~ 187] ~ ~ ~ \varepsilon ́ \pi \alpha v \tau \varepsilon ́ \lambda \lambda o v \sigma \alpha ~} \Sigma \varepsilon \lambda \eta \dot{v \eta ~[M u s a e . ~ 57]), ~ e i n z e l n e ~ G e-~}$

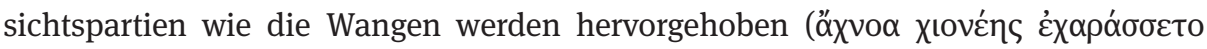

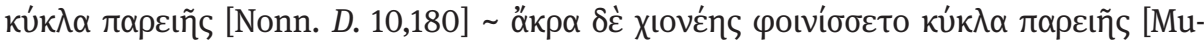

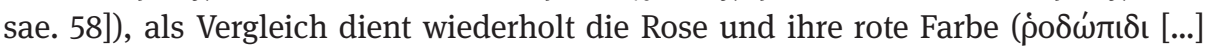

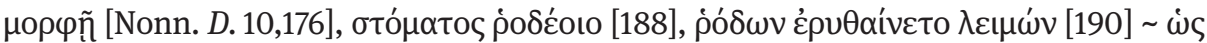

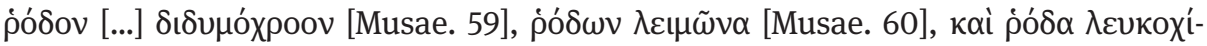

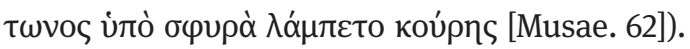

Abgesehen von den Parallelen auf lexikalischer und thematischer Mikroebene wäre auch eine detaillierte Untersuchung der Einordnung derartiger Motive in die Gesamtkomposition des jeweiligen Werkes vielversprechend. Nonnos setzt die Vegetationsmotivik in den größeren Kontext um die Genese des Weines und liefert gleichsam eine Teil-Kosmogonie der dionysischen Welt, indem er der für das dionysische Wirken zentralen Pflanze ein eigenes Aition widmet. Der Weinstock steht stellvertretend für die Erschaffung der Flora insgesamt, die Etablierung des Dionysos für die Erneuerung der Welt. Ein gesteigertes Interesse an kosmologisch-kosmogonischen Fragestellungen ist auch bei den Autoren aus Gaza zu bemerken. Die Gazener Philosophen-Trias des 5. und 6. Jhs. n. Chr., Aeneas, Zacharias und Prokopios, beschäftigt sich, angeregt durch die Werke Platons, verstärkt mit Kosmogonie, ${ }^{85}$ und mit

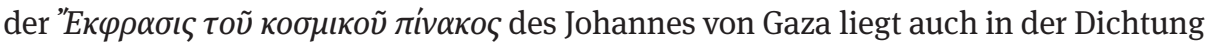
eine Auseinandersetzung mit ebendieser Thematik vor. ${ }^{86}$ Die Tradition ließe sich ohne

83 Vgl. S. $169-172$.

84 Vgl. Procop. Gaz. Op. I (= Dial. 1); Op. II (= Dial. 2); zu Johannes von Gaza siehe Ciccolella (2000); vgl. auch Chor. XVI (= Dial. 9) und XXXIX (= Dial. 24) Foerster u. Richtsteig.

85 Vgl. dazu ausführlich Champion (2014); zu Aeneas von Gaza siehe auch Wacht (1969).

86 Auch Johannes von Gaza bedient sich bevorzugt der Vegetationsmotivik, vgl. Jo. Gaz. 2,1-6: Kaì

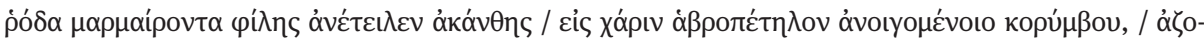

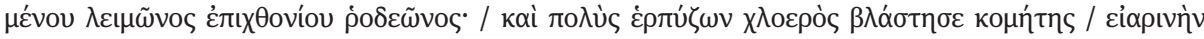

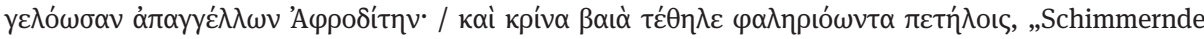
Rosen sproßten aus ihrem Dornstrauch, und zu zartblättriger Anmut öffnete sich die Knospe, da die bunte Pracht des Rosenstockes gedörrt (d. h. erwärmt) ward. Reichlich am Boden kriechend wuchs das grüne Haarkraut (?), das die lachende Aphrodite des Frühlings verkündet, und kleine Lilien erblühten mit weißen Blättern“, Text und Übersetzung: Friedländer (1912) 151, 191. 
Schwierigkeiten auch in byzantinische Zeit weiterverfolgen, an dieser Stelle gilt es lediglich festzuhalten, dass die Werke des Nonnos an einem Scheitelpunkt zwischen Antike und Mittelalter anzusiedeln sind, der Dichter selbst ist Brücke zwischen Alt und Neu, nonnianisches Dichten ist zugleich antikes, spätantikes und byzantinisches Dichten. ${ }^{87}$

\subsection{Christliche Einflüsse}

\section{Der heidnisch-christliche Synkretismus der Spätantike und die Dionysiaka}

Ein Hauptmerkmal für das 4., 5. und 6. Jh. n. Chr. sind die intensiven wechselseitigen Auseinandersetzungen zwischen Christen- und Heidentum; Christliches und Heidnisches wird kombiniert, und christliche Literatur bedient sich heidnischer Stil- und Kompositionselemente, da die Angehörigen beider Konfessionen auf eine gemeinsame intellektuelle Basis zurückgreifen können. ${ }^{88}$ Kirchenmänner und christliche Dichter schöpfen aus einer über ein Jahrtausend währenden Tradition und verwenden diese, je nach Bedarf und Textsorte, für antiheidnische Polemik oder, losgelöst von jeglicher konfessioneller Konnotation, als künstlerisches Versatzstück für ihre klassizistischen Literaturwerke. So finden sich etwa bei Prudentius auch die heidnischen Horen, ${ }^{89}$ und in der griechischen Literatur gelingt Gregor von Nazianz eine perfekte Synthese christlicher Inhalte sowie heidnischer Formen und Mythen. ${ }^{90}$ Die Beschäftigung mit

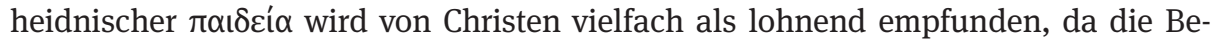
herrschung literarischer und rhetorischer Techniken als beste Schule für die eigene literarische Produktion angesehen wird. ${ }^{91}$

Nonnos liefert mit der hexametrischen Paraphrase des Johannes-Evangeliums eines der wenigen vollständig erhaltenen griechischen Bibelepen, in das er zahlreiche klassisch-pagane Elemente einflicht und so ein synkretistisches Ganzes kreiert, freilich unter dem Vorrang der christlichen Ideologie. Christliche Dichtungen wie das Bibelepos sprechen nicht nur ein christliches, sondern auch ein heidnisches Publikum an, das in einen kulturellen Dialog mit der anderen Konfession tritt. ${ }^{92}$ Eine analoge Situation liegt in der Ikonographie der spätantiken bildenden Kunst vor: Ein beliebtes

87 Eine exemplarische Darstellung der Wirkung des Nonnos in Byzanz findet sich bei De Stefani (2014); zur Charakterisierung nonnianischer Poetik als spätantik-byzantinisch vgl. Averincev (1988) $187-207$.

88 Vgl. Abel-Wilmanns (1977) 191-203; Kennedy (1983) 185 f., 214; Springer (1988) 31; Kahlos (2007) 3-60, 57: „Pagans were needed in the construction of Christian identity.“

89 Vgl. Malamud (1989) 79-113.

90 Vgl. Ševčenko (1980) 57-60; Kennedy (1983) 215-238; Kennedy (1994) 261-263; Demoen (1996) 201 - 205, 302, 321f.; Cribiore (2007a) 166-168.

91 Vgl. Roberts (1985) $62 \mathrm{f}$.

92 Vgl. Herzog (1975) 159f.; Smolak (1984); Charlet (1988) 82 - 84; Agosti (2009a); Whitby (2013) 210-212; Accorinti (2016a). 
Thema der Sarkophag- und Mosaikkunst ist der Weingott Dionysos mit seinen Begleitern, das sich nicht selten auch in christlichem Kontext wiederfindet; ${ }^{93}$ einzelne mythische Figuren wie Dionysos oder Herakles können auch losgelöst von ihren paganen Wurzeln verstanden werden und den Rezipienten zur Identifikation mit der hellenischen Kultur dienen, ${ }^{94}$ oder aber sie werden in christlich-allegorischem Sinne umgedeutet und $\mathrm{zu}$ Botschaftern christlicher Heilsgeschichte. ${ }^{95}$

Auf dieser Basis wurde Dionysos - auch die Dionysos-Figur in den Dionysiaka von christlichem Standpunkt aus gleichsam als heidnischer Archetyp für Christus angesehen: „Nelle Dionisiache il dio è insieme signore giusto e saggio, autorità garante dell’ordine cosmico ma anche guerriero e triumphator."96 Als Aufhänger für die christliche Interpretationslinie diente immer wieder folgendes, bereits von John B.

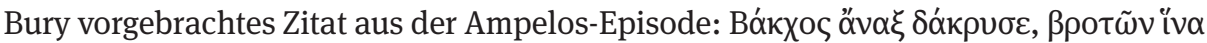

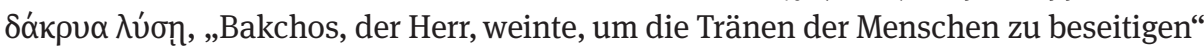
(Nonn. D. 12,171). ${ }^{97}$ Joseph Golega stellte im Rahmen seiner Untersuchungen zur $\mathrm{Pa}$ raphrase weitere Entsprechungen zwischen Passagen der Dionysiaka und des Johannes-Evangeliums fest; in der Ampelos-Episode sind folgende von besonderer Bedeu-

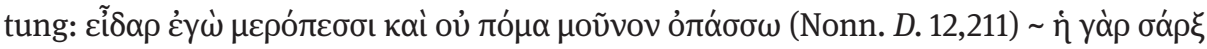

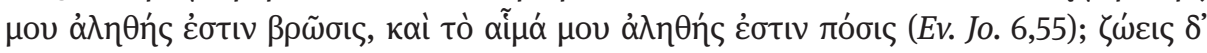

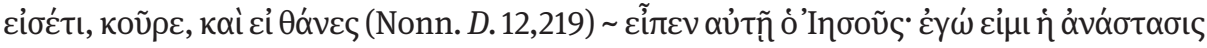

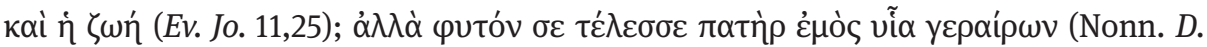

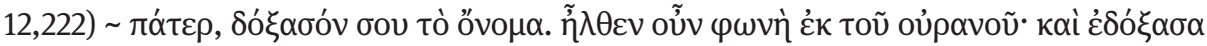

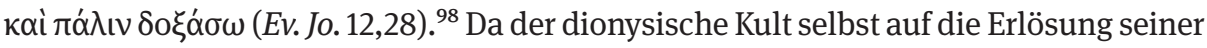
Anhänger hin ausgerichtet ist ${ }^{99}$ und auch orphische Traditionen bei einer Untersuchung der Dionysiaka und der Ampelos-Episode mit berücksichtigt werden müssen, darf der soteriologische Zug keineswegs vor einem ausschließlich christlichen Hintergrund gesehen werden.

Schon die Nonnos-Forschung am Beginn des 20. Jhs. wollte die Dionysiaka nicht primär konfessionsorientiert verstanden wissen: Viktor Stegemann sah im nonnianischen Dionysos nicht so sehr einen Weltenherrscher der Endzeit nach christlichem Vorbild als vielmehr einen Repräsentanten spätantiker autokratischer Herrschaftsformen. ${ }^{100}$ Auch Wolfgang Liebeschuetz relativierte die Einschätzung der Dionysiaka als religiöses Epos und legte stattdessen den Schwerpunkt auf Nonnos’ Anspruch auf

93 Vgl. Foucher (1981); Willers (1992); Gelzer (1993); Willers (1993); Carpenter (1997).

94 Bowersock (1990) 41 - 53; Thomas (2000) 36 - 38, 60 f.; Bowersock (2006) 38 - 47; Hernández de la Fuente (2008) 19-23; Ferrari (2011) 211-213.

95 Vgl. Herzog (1975) 155; Roberts (1985) 178; zu allegorisch-exegetischen Lesarten griechischer Klassiker in der Spätantike vgl. Agosti (2005a).

96 Ferrari (2011) 212; vgl. auch Thomas (2000) 63; Hernández de la Fuente (2013a).

97 Vgl. Bury (1889) Bd. 1, 318f.; Hernández de la Fuente (2008) 223 f.; Accorinti (2013) 1120.

98 Vgl. Golega (1930) 69f.; Chuvin (2014) 15.

99 Vgl. Fauth (1981) 29f., 193; Blázquez (1993) 559f.; Gigli Piccardi (2003) 377.

100 Vgl. Stegemann (1930) 183-195. 
poetische Universalität, die sämtliche literarische Gattungen und Ausdrucksformen der klassischen sowie der ausgehenden Antike, folglich auch christliche Elemente, in sich aufnehme: „In fact it is a mistake to interpret the Dionysiaca as primarily a religious poem. What it undoubtedly is, is a very learned poem. "101 In der jüngeren Forschung, etwa bei Konstantinos Spanoudakis, wird der Aspekt des Synkretismus von christlichen und paganen Elementen im Werk des Nonnos betont; ${ }^{102}$ neben lexikalischen Anklängen an die Bibel und der Verwendung einzelner Motive und Szenen werden auch ganze narrative Strategien dem christlichen Umfeld entlehnt und in den heidnischen Mythos eingepasst. In dieser Weise dürfen auch die christlichen Reminiszenzen verstanden werden, die in der Ampelos-Episode zu finden sind. Nonnos konzipierte seine Schlüsselstelle der Dionysiaka nicht auf der christlichen Lehre als unverbrüchlichem Fundament, sondern griff lediglich auf ein Kulturgut zurück, das zu seiner Zeit bereits dem Standardrepertoire jeglicher poetischer Äußerung zuzurechnen war. Diese Synthese von Heiden- und Christentum in der ausgehenden Antike verbietet eine strikte Unterscheidung von paganer und christlicher Poetik. ${ }^{103}$ Die zahllosen Berührungspunkte zwischen heidnischen und christlichen Dichtungen in den Bereichen der Lexik, Stilistik, Motivik und Narrativik erlauben vielmehr von einem spezifisch spätantiken Idiom zu sprechen, in dem Heidnisches christianisiert und Christliches auf höchstem künstlerischen Niveau mit Heidnischem verbrämt wird.

\section{Christliches in der Ampelos-Episode?}

Spätantike Dichtung, sei sie nun primär heidnisch oder christlich, bricht mit den Normen des klassischen Epos und verfolgt eine von diesem völlig unterschiedliche Ästhetik des Erzählens. Christliches Wortmaterial, Motive und Szenen sowie Elemente der biblischen Erzähltechnik halten auch in die pagane Literatur Einzug, und die christliche Literatur bedient sich zahlreicher Vorbilder aus der klassischen Antike. ${ }^{104}$ Daher scheint es treffender, von spätantiker Dichtung als von einer christlichen oder paganen Dichtung zu sprechen.

101 Liebeschuetz (2001) 232; vgl. auch McLynn (2009) 585: „,...] the vast Dionysiac epic by Nonnus of Panopolis has been stripped of any religious overtones by recent commentators; “ vgl. auch Frangoulis (2008) 290: „[...] il serait imprudent d'en conclure que Nonnos témoigne ici d'une foi chrétienne sincère ou d'une croyance en la mission rédemptrice de Bacchos.“

102 Vgl. Spanoudakis (2007), der diese poetische Verfahrensweise am Beispiel der Ikarios-Episode in den Dionysiaka veranschaulicht; siehe außerdem Hernández de la Fuente (2007a).

103 Vgl. Roberts (1985) 180: „Christianity and the classical literary tradition, transmitted as it is through the schools of late antiquity, work in unison; they are no longer felt to be at odds. For this reason it is often impossible to attribute exclusively Christian motivation to a stylistic feature or literary technique“; vgl. auch Chuvin (2014) 12-18.

$104 \mathrm{Zu}$ den unterschiedlichen Ebenen der Rezeption des Christentums in den Dionysiaka vgl. Spanoudakis (2007) 83. 
Das lexikalische Material entlehnt Nonnos auch in der Ampelos-Episode teilweise

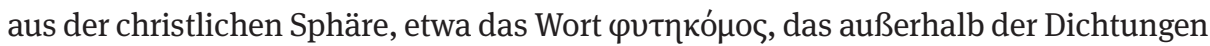
des Nonnos vornehmlich in christlichem Kontext zu finden ist. ${ }^{105}$ Bei Nonnos ist es achtmal in den Dionysiaka belegt, davon zweimal in der Ampelos-Episode, sowie zweimal in der Paraphrase (Nonn. D. 7,303; 11,366; 12,23; 22,90; 26,191; 42,304; 44,218; 47,66; Nonn. P. 18,8; 20,67). ${ }^{106}$ Die beiden Stellen in der Ampelos-Episode sind jeweils im Lichte des Kommens der Weinpflanze zu lesen: In Nonn. D. 11,366 spendet Eros Dionysos Trost mit dem Verweis auf Ampelos' bevorstehende Metamorphose, und in Nonn. D. 12,23 wird Helios mit diesem Epitheton bedacht, wodurch seine Funktion als Lenker des Wachsens und Gedeihens sämtlicher Pflanzen (auch des Weines) her-

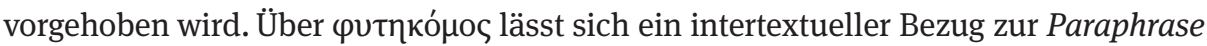
herstellen: Die paradiesische Garten-Idylle, in die sich Jesus am Beginn des 18. Buches begibt, ist Vorwegnahme seiner Auferstehung; die in dieser Umgebung unmittelbar im Anschluss an die Ekphrasis stattfindende Festnahme Jesu unter Mitwirkung des Judas bildet einen starken negativen Kontrast zur positiv besetzten Naturkulisse und zu-

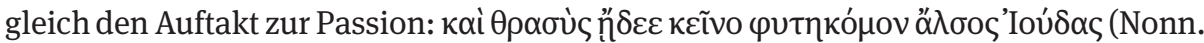
P. 18,8). Den Höhe- und Endpunkt erreicht die Leidensgeschichte Jesu mit seiner Auferstehung im 20. Buch, wo die Bedeutsamkeit des Geschehens vom Dichter wiederum durch $\varphi$ $\tau$ кó $\mu$ о markiert wird; die am Grab Jesu trauernde Maria von Magdala

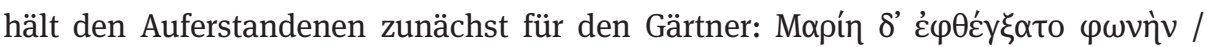

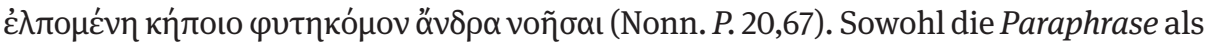
auch die Dionysiaka arbeiten auch auf der lexikalischen Mikroebene auf die Auferstehung Christi und die Genese des Weines nach dem Tod des Ampelos hin.

Weitere Anregungen für die Konzeption seiner Ampelos-Episode erhält Nonnos auch aus der christlichen Erzähltechnik. Obwohl sowohl die heidnische als auch die christliche Literatur reichlich aus den rhetorischen Traditionen schöpfen, die über die höchst konservative Schulbildung bis in die Spätantike und darüber hinaus ins byzantinische Mittelalter vermittelt wurden, entwickelt sich aus dem biblischen Kontext heraus auch eine Rhetorik christlicher Prägung, ${ }^{107}$ deren besonderes Kennzeichen die Irrelevanz logischer Schlussfolgerungen ist, wie sie noch für die klassisch-heidnische Rhetorik unabdingbar war. Biblische Passagen wie die Bergpredigt Jesu oder auch die Paulus-Briefe dienen christlichen Predigern und Homiletikern als Musterbilder, Stilprinzipien wie Vergleiche, kontrastierende Gegenüberstellungen und hymnenartige Loblieder werden einer argumentativen Beweisführung vorgezogen, die sprechende Figur wird zum Sprachrohr Gottes und soll das Publikum von dessen unantastbarer

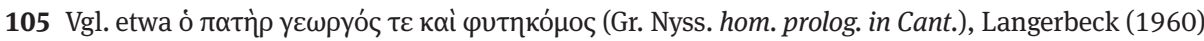
10, 16 f.; außerdem Gr. Nyss. hom. 4 in Cant., Langerbeck (1960) 98, 4; Jo. Gaz. 2,122. - Suid. $\varphi 877$

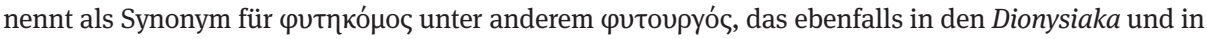
der Paraphrase gebraucht wird, vgl. dazu Spanoudakis (2007) 40.

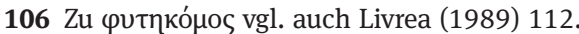

107 Vgl. Kennedy (1983) 180 - 183; Cameron Averil (1991) 48; Kennedy (1994) 258; Kennedy (1999) $142-147$. 
Autorität und Allmacht überzeugen. Die oftmals umfangreichen Reden im spätantiken Bibelepos dienen der Ausgestaltung und Dramatisierung theologisch bedeutsamer Szenen. ${ }^{108}$

Die logischen Inkonsequenzen in der narrativen Konzeption der Ampelos-Episode könnten zudem von der jüdisch-alttestamentarischen Tradition der Doppelerzählung inspiriert sein. Die beiden Alternativversionen der Entstehung des Weinstocks bei Nonnos erinnern an die beiden unterschiedlichen Erzählungen über die Genese des Menschen in der Genesis: (1.) die Erschaffung Adams durch das Wort Gottes (LXX Ge. 1,26-30), und (2.) seine Formung aus Lehm (LXX Ge. 2,4-7). ${ }^{109}$ Das Vorhaben, ein Epos über das Leben und Wirken einer heiligen Person sowie deren Aufnahme in den Himmel zu verfassen, könnte außerdem durch das christliche Genus der Heiligenvita angeregt worden sein, das im Unterschied zur klassisch-heidnischen Geschichtsschreibung mythisch-historische Begebenheiten nicht in annalistischer oder pragmatischer, sondern in biographisch-hagiographischer Form darbietet. Dennoch ist bei solchen Interpretationen Vorsicht geboten, da in der Kaiserzeit auch in der paganen Literatur eine besondere Hochschätzung der Gattung der Biographie zu beobachten ist. Ferner darf der Bilder- und Metaphernreichtum der christlichen Sprache ebenso als Anhaltspunkt für das nonnianische Dichten angenommen werden wie die Bedeutsamkeit von Schriftlichkeit und Exegese. ${ }^{110}$ Die besondere Relevanz von Schrift und Schriftlichkeit, die für das Christentum insgesamt kennzeichnend ist, wird in der Ampelos-Episode an den Tafeln der Harmonia augenscheinlich. ${ }^{111}$

Um Anlehnungen an die biblische Formensprache handelt es sich möglicherweise auch bei einigen Motiven, die an Jesu Leben, Leiden und Auferstehung erinnern: Das Bad, das Dionysos zu Beginn der Episode im Paktolos nimmt, knüpft einerseits an heidnische Badeszenen wie die des Achill oder Alexanders des Großen an, andererseits erinnert es wohl auch an die Taufe Jesu im Jordan. ${ }^{112}$ Die christlich-eucharistische Symbolik der Ampelos-Episode wird zusätzlich durch die Kombination von Wasser und Wein evoziert: Vom einleitenden Bad der Satyrn im Paktolos bis zur Entstehung des Weines durch Ampelos' Metamorphose vollzieht sich in der Erzählung gleichsam eine Wandlung von Wasser zu Wein; die in der Wasser-Szene genannten Fische fügen sich gleichfalls in diese Symbolwelt. Das Wasser-Wein-Motiv findet sich auch in der Szene mit der Samariterin am Brunnen des Jacobus in Nonn. P.4,13-19 wieder, welche sich ähnlich wie die erste Szene in der Ampelos-Episode in der Mittagshitze abspielt

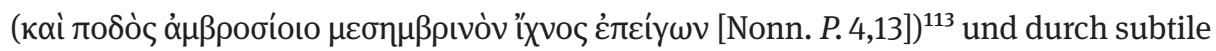

108 Vgl. Roberts (1985) 145-148.

109 Vgl. Roberts (1985) $127-130$.

110 Zur Beliebtheit von Metaphern in der christlichen Literatur vgl. Cameron Averil (1991) 58-60: „Metaphor is at the heart of the Christian language“; zur christlichen Bildersprache siehe Springer (1988) 92-95; zur Exegese vgl. Springer (1988) 84-90; Haines-Eitzen (2009); zur Bedeutung von Schriftlichkeit in der Spätantike vgl. Stroumsa (2014).

111 Vgl. auch Hermes und die lateinischen Gesetzestafeln (Nonn. D. 41,159f.); Averincev (1988) 256. 112 Vgl. Bowersock (2011). 
Anspielungen auf lexikalischer Ebene die eucharistische Symbolik des Weines vor-

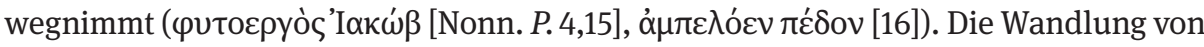
Wasser zu Wein wird schließlich in der Weinwunder-Szene bei der Hochzeit zu Kana in Nonn. P. 2 vollzogen und findet sich auch in den Dionysiaka am Beginn des IndienKrieges, wenn die indischen Krieger durch Wein kampfunfähig gemacht werden (vgl. Nonn. D. 14,411-437; 15,1-118). ${ }^{114}$ Doch auch hier ist Vorsicht geboten, da die Verwandlung von Wasser in Wein nicht notwendigerweise christlich verstanden werden muss, sondern an philosophisch-religiöse Tendenzen der Spätantike wie den Neuplatonismus anknüpfen kann. ${ }^{115}$ Durchaus ambivalente Bedeutung hat auch die rote Farbe des Weines: Die Farbe Rot ist zum einen in der heidnischen Literatur erotisch konnotiert, zum anderen mit christlich-theologischer Bedeutung versehen. ${ }^{116}$ Diese Doppelbödigkeit findet sich allenthalben in den Dionysiaka; die zugrunde liegende pagane Mythologie wird um eine spezifisch christliche Lesart erweitert, die die Rezeption auch durch ein christliches Publikum nahelegt.

Ein weiterer Themenkomplex, der sich sowohl in der Ampelos-Episode als auch in christlichen Kontexten findet, sind Heilungen und Wunder, Erlösungen und Auferstehungen: Wundersame Heilungen wie die durch Aristaios' Honig (Nonn. D. 17,357384) oder die Auferstehung des Tylos ${ }^{117}$ fügen sich in die große Erzähllinie über die Wiederauferstehung und Apotheose des Dionysos. ${ }^{118}$ In der Paraphrase des JohannesEvangeliums bildet die Wiederauferweckung des Lazarus (Nonn. P. 11,1-185) die Präfiguration der Auferstehung Christi. Die besondere Verfahrensweise des Nonnos lässt sich anhand der Szenen um Ampelos und Lazarus exemplifizieren: ${ }^{119}$ Die Auferstehungs-Thematik wird in beiden Fällen durch ein und dasselbe Adjektiv bestimmt;

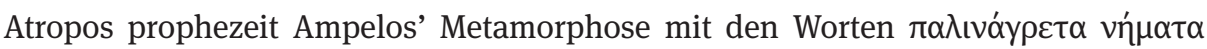

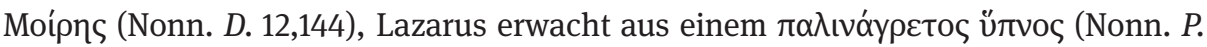

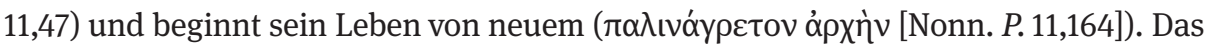
Adjektiv findet sich auch an anderen Stellen beider Werke: Schon in Nonn. P. 5,82

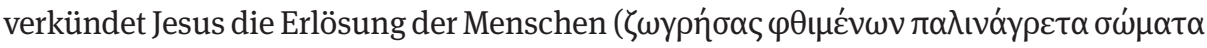
$\varphi \omega \tau \tilde{\omega} v)$, und auch auf seine eigene Wiederauferstehung wird dadurch verwiesen

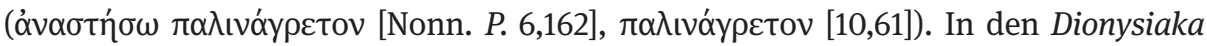

113 Vgl. De Stefani (1999) $340 \mathrm{f}$.

114 Zur Szene um die Hochzeit von Kana in der Paraphrase vgl. Caprara (2005) 9f.

115 Vgl. Caprara (2005) 10-15.

116 Vgl. Chuvin (2009a) 480.

$117 \mathrm{Zu}$ Tylos vgl. S. $238-240$.

118 Vgl. Haidacher (1949) 78; Hernández de la Fuente (2008) 213-215, 221-224; Franchi (2013) 124; Accorinti (2015) 61 - 67; siehe auch die Zusammenstellungen in Hernández de la Fuente (2007a) 181-186 und Hernández de la Fuente (2013a); zu den Wundererzählungen in der Bibelepik des Sedulius vgl. Springer (1988) 64-67.

119 Zum 11. Buch der Paraphrase mit der Lazarus-Szene vgl. Spanoudakis (2014b) mit Edition, englischer Übersetzung und ausführlichem Kommentar; Spanoudakis (2014b) 41 konstatiert nur lockere Assoziationen und einzelne lexikalische und typologische Entsprechungen zwischen beiden Szenen und sieht im Schicksal des Ampelos keinerlei soteriologisches Heilsgeschehen. 
kommt das Adjektiv in Nonn. D. 3,255 in Elektras Rede über die zyklische Wiederkehr vor, ebenso bei der Erweckung des Tylos in Nonn. D. 25,545. Aber auch poetische Periphrasen für Tod und Wiederauferstehung sind nichts genuin Christliches, ${ }^{120}$ sondern auch in paganen Kontexten wie im Falle des Tylos zu finden, der ähnlich wie Jesus Christus oder Ampelos in veränderter Gestalt weiterlebt und wieder zum Leben erweckt wird.

Mit derartigen Figuren kann sich der Dichter frei zwischen den unterschiedlichen Traditionen - christlichen und heidnischen - bewegen und je nach Bedarf mit mythologischen und literarischen Topoi jonglieren. Das stete Abgleichen seiner eigenen poetischen Innovationskraft mit den Dichtungstraditionen vergangener Jahrhunderte bildet den Kern seiner Poetik. Auf der Grundlage wörtlicher Zitate insbesondere aus den homerischen und hellenistischen Dichtungen sowie durch die Entlehnung traditioneller Themen und Motive gelingt ein intertextuelles Spiel mit den zu seiner Zeit schon lange zu Klassikern gewordenen Repräsentanten der griechischen Literatur. Mit den Dionysiaka und der Paraphrase tritt der Panopolitaner in eine schöpferische Konkurrenz zu literarischen Referenztexten wie Ilias und Odyssee, den Argonautika oder den kallimacheischen Hymnen und zugleich auch in Dialog mit zeitgenössischen Tendenzen wie den neuen religiösen Ausdrucksformen des Christentums, die in der spätantiken Dichtung ihren Niederschlag finden. Durch seine besondere Affinität zu enzyklopädisch-philologischer Gelehrsamkeit, poetologischer Reflexion und Bildhaftigkeit in der Darstellung sowie durch die Anlage eines ausgedehnten Netzes von inter- und intratextuellen Anspielungen schließt Nonnos an hellenistische Traditionen an und geht gleichzeitig auch über diese hinaus. Mit dem Aufbrechen der Gattungsgrenzen und der Aufnahme anderer Genera ins Epos erweist er sich einmal mehr als Dichter der Kaiserzeit und der Spätantike, die sich, losgelöst von der klassischen Antike und dem Hellenismus, als eigene Epoche verstanden wissen will: „Il faudrait enfin consenter à admettre que l'antiquité tardive n'est pas seulement l'ultime phase d'un développement continu; c'est une autre antiquité, une autre civilization, qu'il faut apprendre à reconnaître dans son originalité et à juger pour elle-même et non à travers les canons des âges antérieurs. “121

Nonnos gelingt es, mit der Ampelos-Episode eine Brücke zwischen Alt und Neu zu schlagen und Altes in neuem Licht zu zeigen. ${ }^{122}$ Es bleibt die Aufgabe künftiger Untersuchungen, die Einbindung und Verankerung der nonnianischen Dichtungen im literarischen Schaffen der Spätantike herauszuarbeiten, um Nonnos, der bereits für seinen Übersetzer Le Comte de Marcellus im 19. Jh. als „le plus oublié des poètes grecs“123 galt, endgültig den ihm gebührenden Platz in der Literaturgeschichte zuzugestehen.

120 Vgl. Roberts (1985) 151-153.

121 Marrou (1977) 13.

122 Vgl. Miguélez Cavero (2009a) 252: „Nonnus maintains a balance between old and new.“

123 Marcellus (1861) 367. 